\title{
HUBUNGAN PERSEPSI PEMBERIAN REWARD TERHADAP KEPUASAN KERJA DAN LOYALITAS KERJA KARYAWAN PADA PEKERJA PENDATANG
}

\author{
Ely Kartikaningdyah ${ }^{1)}$, Fatimah Rima Ramadhani ${ }^{2)}$ \\ Prodi Akuntansi Manajerial Politeknik Negeri Batam, ely@polibatam.ac.id \\ Prodi Akuntansi Manajerial Politeknik Negeri Batam, rimaramadhani25@gmail.com
}

\begin{abstract}
This study examines the extrinsic and intrinsic reward relationship to job satisfaction and loyalty work in manufacturing companies in Batam. The reward system consists of a reward desired and expected reward either extrinsic or intrinsic. Job satisfaction can be met if the reward system fair and equitable to all workers according to their contribution to the company and will reduce labor turnover because of their loyalty to the company's labor and employment. Respondents in this study were 239 labor migrants working in manufacturing companies in Batam that reside in the Flats Muka Kuning, an analytical technique used is the analysis of correlation and independent test samples t-test. The results of the hypothesis: there is a positive and significant relationship between reward extrinsic and reward intrinsically desirable to job satisfaction and loyalty work, there is a relationship reward extrinsic and rewards intrinsic to expect on job satisfaction and loyalty work and not there are reward differences in perception between men and women on job satisfaction.
\end{abstract}

Keywords: rewards, job satisfaction, loyalty work, gender, manufacturing companies, migrants

\begin{abstract}
Abstrak
Penelitian ini meneliti mengenai hubungan reward ekstrinsik dan reward intrinsik terhadap kepuasan kerja dan loyalitas kerja pada perusahaan manufaktur di batam. Pemberian reward terdiri dari reward yang diinginkan dan reward yang diharapkan baik berupa ekstrinsik maupun intrinsik. Kepuasan kerja dapat terpenuhi jika pemberian reward adil dan merata ke setiap tenaga kerja sesuai dengan kontribusinya terhadap perusahaan dan dapat mengurangi perputaran tenaga kerja dikarenakan adanya loyalitas tenaga kerja terhadap perusahaan dan pekerjaan. Responden dalam penelitian ini adalah 239 tenaga kerja pendatang yang bekerja di perusahaan manufaktur di batam yang bertempat tinggal di Rumah Susun Muka Kuning, teknik analisa yang digunakan adalah analisis korelasi dan uji Independen sampel t-test. Hasil penelitian menunjukkan terdapat hubungan positif dan signifikan antara reward ekstrinsik dan reward intrinsik yang diinginkan terhadap kepuasan kerja dan loyalitas kerja,terdapat hubungan reward ekstrinsik dan reward intrinsik yang diharapkan terhadap kepuasan kerja dan loyalitas kerja,terdapat perbedaan persepsi pemberian reward intrinsic terhadap berdasarkan gender terhadap kerpuasan kerja dan tidak terdapat perbedaan persepsi pemberian reward ekstrinsik berdasarkan gender terhadap kepuasan kerja.
\end{abstract}

Kata Kunci: reward, kepuasan kerja, loyalitas kerja, gender, perusahaan manufaktur, tenaga kerja pendatang. 


\section{PENDAHULUAN}

Batam sebagai kota industri bisa dilihat dari segi pembangunannya dan perusahaanperusahaaan yang berdiri yang mengisyaratkan terbukanya lapangan pekerjaan. Hal ini yang membuat daya tarik bagi pendatang untuk mencari pekerjaan dan penghidupan yang layak di kota Batam. Migrasi ini yang menyebabkan kota Batam menjadi salah satu kota yang pesat akan pertumbuhan penduduknya di Indonesia. Pendatang tersebut terdiri dari pria dan wanita. Pendatang tersebut bertempat tinggal di rumah susun yang telah disediakan oleh perusahaan tempat mereka bekerja.

Selain menerima gaji, tenaga kerja juga menerima pemberian reward yang sesuai dengan kemampuan dan kontribusi tenaga kerja terhadap tugas dan tanggung jawabnya terhadap perusahaan. Secara umum, gaji belum tentu mampu mencukupi kebutuhan hidup setiap tenaga kerja. Kebutuhan setiap individu sangat bervariasi. Kenaikan harga-harga kebutuhan baik yang pokok maupun pendukung biasanya tidak diikuti dengan kenaikan gaji. Oleh karena itu, pemberian reward sangat dibutuhkan oleh setiap tenaga kerja. Reward adalah sesuatu yang diterima oleh tenaga kerja sebagai tambahan atau pengganti terhadap kontribusi yang melebihi tanggung jawabnya kepada perusahaan. Pemberian reward terdiri dari reward yang diinginkan dan reward yang diharapkan baik berupa ekstrinsik dan intrinsik. Reward yang dirasakan merupakan penilaian evaluatif yang berupa manfaat finansial dan non-finansial yang diterima tenaga kerja hasil dari kinerjanya dengan perusahaan (Newman and Sheikh, 2012). Sistem pemberian reward juga dapat membantu pencapaian tujuan organisasi.

Loyalitas merupakan tekad dan kesanggupan untuk mentaati, melaksanakan sesuatu yang ditaati dengan penuh kesadaran dan tanggung jawab (Flippo, 1996). Loyalitas merupakan unsur penting yang diharapkan oleh setiap perusahaan kepada tenaga kerjanya. Loyalitas bukan berdasarkan lama atau tidaknya seorang tenaga kerja bekerja pada perusahaan tersebut melainkan didasarkan pada kesetiaan dan rasa tanggung jawabnya terhadap pekerjaan dan memberikan yang terbaik bagi perusahaan agar tercapainya tujuan utama perusahaan.

Perbedaan penelitian dari peneliti sebelumnya (To dan Tam 2013) adalah mengambil responden berdasarkan gender yaitu laki-laki dan wanita pekerja pendatang yang bekerja pada sektor manufaktur di wilayah kota Batam dan menambahkan variabel loyalitas kerja karyawan sebagai hasil dari pemberian reward melalui kepuasan kerja.

Berdasarkan latar belakang yang telah dijelaskan, pemberian reward intrinsik dan reward ekstrinsik mempengaruhi kepuasan kerja karyawan maka menjadi suatu dasar bagi penelitian ini untuk memfokuskan suatu perumusan masalah adalah pertama, apakah terdapat hubungan positif pemberian reward intrinsik dan ekstrinsik yang diharapkan terhadap kepuasan kerja dan loyalitas kerja. Kedua, apakah terdapat hubungan positif pemberian reward intrinsik dan ekstrinsik yang diinginkan terhadap kepuasan kerja dan loyalitas kerja. Pemberian reward ini digunakan untuk balas jasa yang diberikan oleh perusahaan dan diterima oleh tenaga kerja. Pemberian reward juga dapat didefinisikan sebagai faktor terbentuknya kepuasan kerja. Loyalitas kerja karyawan sangat penting untuk diperhatikan oleh setiap perusahaan yang menginginkan tenaga kerjanya setia untuk tetap bekerja di perusahaan tersebut. Penelitian ini juga menguji apakah terdapat perbedaan persepsi pemberian reward yang diinginkan dan diharapkan terhadap kepuasan kerja berdasarkan perbedaan gender yaitu laki-laki dan perempuan.

\section{Kajian Pustaka Persepsi}

Persepsi merupakan proses pemberian tanggapan, gambaran dan arti terhadap apa yang didengar, dirasakan dan dilihat yang disampaikan oleh seseorang dalam bentuk pendapat, sikap dan tingkah laku. Perbedaan dan keunikan individu pada tiap orang dapat menghasilkan proses kognitif. Proses kognitif dapat berupa imajinasi, persepsi dan bahkan dalam bentuk pemikiran (Luthans, 2005).

\section{Migrasi Penduduk \\ Teori Migrasi}

Teori Income Harapan

Todaro mengembangkan teori migrasi yang disebut teori income harapan. Teori income harapan dimaksudkan bahwa seseorang masih mempunyai harapan mengenai income yang lebih tinggi daripada sektor pertanian. Menurut todaro, alasan migrasi dari desa ke kota karena dikota mempunyai bermacammacam pekerjaan yang dapat meningkatkan harapan income yang lebih tinggi. 
Teori Berantai

Menurut teori ini berlangsungnya proses migrasi di suatu daerah tidak terlepa $\mathrm{s}$ dari kaitannya eksistensi atau pendapat sanak saudara yang tinggal di suatu daerah tersebut. Migrasi pemula sebagai pionir yang menarik penduduk dari daerah asal untuk bermigrasi yang mengakibatkan timbulnya migrasi berantai (chain migration).

\section{Reward}

Menurut Wibowo (2012), Reward merupakan balas jasa atau tambahan penerimaan yang diberikan oleh perusahaan kepada tenaga kerja untuk menghargai kinerja pekerjanya.

\section{Reward yang diharapkan}

Teori Harapan ( Expectancy Theory )

Teori ini dikemukakan oleh Victor $\mathrm{H}$. Vroom (1964) menyatakan kekuatan yang memotivasi seseorang untuk bekerja giat dalam mengerjakan pekerjaannya tergantung dari hubungan timbal balik antara apa yang diinginkan dan dibutuhkan dari hasil pekerjaan itu. Teori harapan didasarkan atas: 1) Harapan (Expentacy) sebagai suatu kesempatan yang diberikan dapat terjadi karena suatu perilaku. 2) Nilai (Valence) adalah akibat dari perilaku tertentu mempunyai nilai tertentu sebagai daya atau nilai motivasi bagi setiap individu yang bersangkutan. 3) Pertautan (Instrumentality) adalah persepsi individu bahwa hasil tingkat pertama. 4) Ekspektensi merupakan sesuatu yang ada dalam diri individu yang terjadi karena adanya keinginan untuk mencapai hasil sesuai dengan tujuan. Kesimpulan teori ini bahwa, seseorang akan memaksimalkan usaha dan meminimalkan segala yang menghalangi demi pencapai hasil yang maksimal.

\section{Pemberian sistem Reward}

Pemberian system reward bertujuan untuk menarik dan mempertahankan sumber daya manusia, karena organisasi memerlukan sumber daya manusia untuk mencapai sasaransasarannya. Pemberian sistem reward yang baik dan menarik mampu meminimalkan jumlah karyawan yang keluar dari perusahaan untuk bergabung dengan perusahaan lain. Tujuan lainnya dari pemberian sistem reward adalah sebagai alat motivasi untuk meningkatkan produktivitas kerja para tenaga kerja serta sebagai pendorong kompetisi yang sehat.

\section{Kepuasan kerja}

Teori Kepuasan Kerja:

1. Teori Hierarki Kebutuhan menurut Abraham Maslow

Asumsi Teori ini yaitu seseorang berusaha memenuhi kebutuhan fisiologis sebelum memenuhi kebutuhan tertinggi berupa realisasi diri. Hal penting dalam teori ini, jika seseorang telah terpenuhi kebutuhannya maka akan menghentikan daya motivasinya.

2. Teori Dua Faktor menurut Herzberg Dalam teori ini, Herzberg mengembangkan teori dua faktor tentang motivasi. Teori ini berasumsi pada factor yang membuat seseorang puas dan tidak puas (ekstrinsik dan intrinsik).

3. Teori Kebutuhan menurut McClelland McClelland mengemukakan bahwa apabila ada kebutuhan seseorang yang mendesak untuk memenuhi kebutuhan tersebut, maka seseorang tersebut akan termotivasi untuk bekerja keras untuk memenuhi kebutuhannya.

Menurut Luthans (2006) ada beberapa dimensi kepuasan kerja yang dapat digunakan untuk mengungkapkan karakteristik penting mengenai pekerjaan, dimana orang dapat meresponnya. Dimensi itu adalah:

1. Pekerjaan itu sendiri: Kepuasan kerja dapat meningkat apabila tenaga kerja tersebut merasa puas dengan pekerjaan yang dikerjakan dapat selesai dengan keahlian yang dibutuhkan dan kesulitan dalam pengerjaannya.

2. Pengawasan: Keramahan atasan untuk meberikan bantuan berupa teknis dan dukungan perilaku terhadap bawahan.

3. Rekan kerja (Workers) adalah faktor yang berhubungan dengan hubungan sosial antara tenaga kerja dan tenaga kerja lain, atasan dan bawahan.

4. Promosi (Promotion) adalah faktor yang berhubungan dengan ada tidaknya kesempatan untuk memperoleh peningkatan karir selama bekerja.

5. Gaji atau Upah (Pay) adalah faktor pemenuhan kebutuhan hidup pegawai yang dianggap layak atau tidak.

Faktor-faktor yang menentukan dan mendorong kepuasan kerja menurut Robbins (2001) yaitu: 1) kerja yang secara mental menantang: Memberikan kesempatan untuk menggunakan keterampilan, kemampuan dan kebebasan dalam mengembangkan hasil kerja serta memberikan umpan balik kepada tenaga kerja 
berupa pujian atau penghargaan. 2) Reward yang pantas: Pemberian sistem upah, kompensasi, bonus dan kebijakan promosi. 3) Kondisi kerja yang mendukung: Kenyamanan pribadi dalam mengerjakan pekerjaan atau faktor-faktor lingkungan yang kondusif. 4) Rekan kerja yang mendukung: Kebutuhan akan interaksi social, perilaku atasan dan minat pribadi.

\section{Loyalitas}

Hasibuan (2001), mengemukakan bahwa loyalitas kerja merupakan salah satu cara sebagai penilaian tenaga kerja yang mencakup kesetiaan terhadap pekerjaannya, jabatannya dan organisasi. Loyalitas para tenaga kerja sangat dibutuhkan demi pencapaian tujuan perusahaan. Semakin tinggi tingkat loyalitas para tenaga kerja terhadap perusahaan maka semakin mudah perusahaan untuk mencapai tujuan-tujuan perusahaan. Menurut Abdullah et al (2011) bahwa pekerja yang mempunyai loyalitas terlibat dalam tujuan perusahaan, bertindak sesuai dengan kesejahteraan jangka panjang perusahaan, dan tidak mencari pekerjaan alternatif atau menanggapi tawaran luar bahkan ketika ditawarkan gaji sedikit lebih tinggi. Tenaga kerja yang setia akan mengurangi biaya perputaran tenaga kerja.

\section{Aspek-aspek loyalitas kerja}

Menurut Alex (2014), aspek-aspek loyalitas kerja terdapat pada individu yang menitikberatkan pada pelaksanaan pekerjaan yang dilakukan oleh tenaga kerja antara lain taat pada peraturan, tanggung jawab pada perusahaan, kemauan untuk bekerja sama dalam menyelesaikan suatu pekerjaan.

\section{Hipotesis}

Penelitian ini mengajukan beberapa hipotesis, adapun hipotesis tersebut disajikan sebagai berikut:

\section{a. Reward Intrinsik dan reward ekstrinsik yang diinginkan terhadap kepuasan kerja karyawan}

Penelitian terkait pengaruh reward intrinsik dan reward ekstrinsik yang diinginkan terhadap kepuasan kerja antara lain dilakukan oleh (Artz, 2010) menghasilkan hubungan positif antara kepuasan kerja dan manfaat, seperti uang, promosi, tunjangan, dan kesempatan untuk belajar keterampilan baru. Penelitian lain dilakukan juga oleh Linz dan Semykina (2011) menunjukkan bahwa di kalangan pekerja di negara sosialis,hubungan sangat kuat ketika berupa imbalan yang diinginkan.

Penelitian lain yang dilakukan oleh Zaini et al (2009) menemukan bahwa kepuasan kerja berhubungan dengan reward intrinsik seperti membayar, promosi, dan bonus dan reward ekstrinsik adalah salah satu variabel penjelas yang paling penting dalam kedua sektor ekonomi dan sosialis. Penulis mengajukan hipotesis sebagai berikut:

H1a: Terdapat hubungan pemberian reward intrinsik yang diinginkan secara positif terhadap kepuasan kerja karyawan.

H1b: Terdapat hubungan pemberian reward ekstrinsik yang diinginkan secara positif terhadap kepuasan kerja karyawan

\section{b. Reward Intrinsik dan reward ekstrinsik yang diharapkan terhadap kepuasan kerja karyawan}

Menurut Linz dan Semykina (2011) bahwa kedua imbalan ekstrinsik dan intrinsik yang diharapkan akan positif terkait dengan kepuasan kerja, reward yang diharapkan akan lebih peduli untuk imbalan moneter daripada imbalan non-moneter. Imbalan moneter memiliki pengaruh yang besar terhadap kepuasan kerja. Wanous et al (1992) mengemukakan bahwa pada kepuasan kerja terdapat harapan yang tinggi. Penelitian lain yang dilakukan oleh Locke (1976) menghubungkan kepuasan kerja dan reward yang diharapkan atau berdasarkan aspek pekerjaan. Penulis mengajukan hipotesis sebagai berikut:

$\mathrm{H} 2 \mathrm{a}$ : Terdapat hubungan pemberian reward intrinsik yang diharapkan secara positif terhadap kepuasan kerja karyawan.

$\mathrm{H} 2 \mathrm{~b}$ : Terdapat hubungan pemberian reward ekstrinsik yang diharapkan secara positif terhadap kepuasan kerja karyawan.

\section{c. Reward Intrinsik dan reward ekstrinsik yang diinginkan terhadap loyalitas kerja karyawan.}

Reward keinginan memiliki konsekuensi bagi loyalitas pekerja, dan jika dimana keinginannya mungkin tidak terpenuhi, seperti promosi atau pekerjaan otonomi, loyalitas cenderung lemah.

Loyalitas akan lebih kuat di antara pekerja yang menunjukkan keinginan mereka untuk meningkatkan proses kerja (Tolbize, 2008). Selain itu, perusahaan dapat 
memberikan pekerjaan kebebasan dengan menilai inovasi dan pengambilan risiko, dan dengan menahan pekerja bertanggung jawab untuk hasil yang sesuai (Wong. et al, 2008).

Linz et al (2013) mengemukakan dalam penelitiannya, hubungan positif yang kuat terhadap loyalitas jelas diantara tenaga kerja yang menginginkan keamanan kerja, pujian dari atasan, dan kesempatan untuk mengembangkan keterampilan baru atau mencapai sesuatu yang berharga. Dalam penelitiannya juga mengemukakan terdapat hubungan positif antara loyalitas dan pendapatan. Kontribusi loyalitas terhadap pendapatan untuk beberapa kelompok pekerja ditemukan menjadi lebih besar dari satu tahun tambahan pelatihan atau pengalaman kerja. Penulis mengajukan hipotesis sebagai berikut:

H3a: Terdapat hubungan reward intrinsik yang diinginkan secara positif terhadap loyalitas kerja karyawan.

H3b: Terdapat hubungan reward ekstrinsik yang diinginkan secara positif terhadap loyalitas kerja karyawan

\section{d. Reward Intrinsik dan reward ekstrinsik yang diharapkan terhadap loyalitas kerja karyawan}

Linz et al (2013) mengemukakan bahwa loyalitas pekerja secara positif terkait dengan sejumlah reward yang diharapkan. Meningkatkan frekuensi atau jumlah bonus yang diberikan kepada tenaga kerja, memberikan kesempatan tambahan untuk mengembangkan keterampilan, dan mengidentifikasi dan mempromosikan kegiatan yang berkontribusi terhadap keamanan kerja juga muncul untuk meningkatkan loyalitas antara tenaga kerja.

Pada saat reward yang diharapkan terpenuhi, tenaga kerja melihat bahwa pimpinan telah memenuhi kewajibannya, dikomunikasikan dalam bentuk eksplisit maupun implisit. Reward yang diharapkan bertemu menyebabkan kepuasan kerja serta komitmen berorganisasi yang akan menimbulkan tindakan loyalitas. Penulis mengajukan hipotesis sebagai berikut:

H4a: Terdapat hubungan reward intrinsik yang diharapkan secara positif terhadap loyalitas kerja karyawan.

H4b: Terdapat hubungan reward ekstrinsik yang diharapkan secara positif terhadap loyalitas kerja karyawan

\section{e. Perbedaan persepsi pemberian reward \\ Intrinsik dan reward ekstrinsik terhadap kepuasan kerja berdasarkan gender yaitu laki-laki dan perempuan.}

Terdapat perbedaan dalam penelitian yang dilakukan oleh Saner dan Eyupoglu (2011) yang menguji perbedaan persepsi pemberian reward Intrinsik dan reward ekstrinsik terhadap kepuasan kerja berdasarkan gender yaitu lakilaki dan perempuan bahwa wanita lebih puas terhadap reward yang diterima daripada lakilaki.

Penelitian lain dilakukan oleh (Bartol, 1976), Mottaz (1985) untuk mengetahui perbedaan persepsi pemberian reward Intrinsik dan reward ekstrinsik terhadap kepuasan kerja berdasarkan gender yaitu laki-laki dan perempuan menunjukkan bahwa pria cenderung lebih memilih reward ekstrinsik dan bahwa wanita cenderung nilai reward intrinsik. Penelitian yang dilakukan oleh Ringkas dan Aldag (1975), Ringkas dan Oliver (1976) menemukan tidak ada perbedaan yang signifikan antara persepsi pemberian reward Intrinsik dan reward ekstrinsik terhadap kepuasan kerja pada laki-laki dan perempuan. Linz et al (2013) mengemukakan dalam penelitiannya bahwa untuk wanita, kepuasan kerja terkait positif untuk kedua ekstrinsik (bonus, pujian dari atasan) dan intrinsik (kesempatan untuk belajar hal baru, kesempatan untuk mencapai sesuatu yang berharga) imbalan, tetapi untuk pria, kepuasan kerja cenderung dikaitkan positif ekstrinsik imbalan diharapkan (bonus, menghormati rekan kerja). Ketika reward keinginan disertakan, imbalan non-moneter wanita lebih puas dibandingkan laki-laki (kesempatan untuk belajar hal-hal baru, kesempatan untuk mencapai sesuatu yang berharga) yang positif terkait dengan kepuasan kerja. Menurut Kaiser (2005) terdapat perbedaan di setiap Negara tentang kepuasan kerja terhadap gender. berikut:

Penulis merumuskan hipotesis sebagai

H5a: Terdapat perbedaan persepsi pemberian reward intrinsik terhadap kepuasan kerja berdasarkan gender yaitu laki-laki dan perempuan.

H5b: Terdapat perbedaan persepsi pemberian reward ekstrinsik terhadap kepuasan kerja berdasarkan gender yaitu laki-laki dan perempuan. 


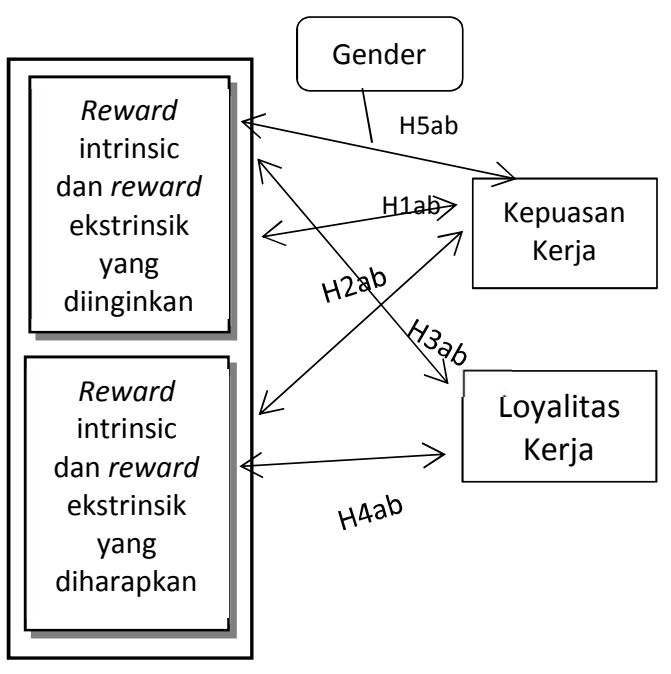

Gambar 1 Model Penelitian Sumber: penulis

\section{METODE PENELITIAN \\ Instrumen Penelitian}

Penulis menggunakan kuesioner penelitian sebagai instrument pengumpulan data. Berdasar kuisioner Linz et al (2013) yaitu variable reward intrinsik dan reward ekstrinsik serta loyalitas kerja karyawan. Kuisioner kepuasan kerja menggunakan penelitian Ma'arif et al (2011). Variabel reward, kepuasan kerja dan loyalitas kerja karyawan diukur menggunakan jenis skala pengukuran data berupa data interval. Skala likert dari masing-masing variabel yang ingin diuji terbagi menjadi 4 skor yaitu: Sangat Tidak Setuju (skor 1), Tidak Setuju (skor 2), Setuju (skor 3), Sangat Setuju (skor 4). Alasan penulis memakai skala likert dengan 4 (empat) kategori jawaban adalah untuk menghindari adanya jawaban netral dan meningkatkan hasil signifikan dari setiap jawaban di kuesioner itu sendiri.

\section{Lokasi dan Objek Penelitian}

Obyek penelitian ini adalah seluruh tenaga kerja perusahaan manufaktur dikhususkan yang bertempat tinggal di kawasan Rumah Susun Muka Kuning. Karakteristik populasi dari penelitian ini adalah tenaga kerja yang bekerja di perusahaan manufaktur khususnya pendatang perempuan dan laki-laki.

\section{Teknik Penetapan dan Penarikan Jumlah Sampel}

Populasi yang diperoleh adalah sebesar 576 tenaga kerja yang terdiri dari laki- laki dan perempuan. Sampel yang ditetapkan berdasarkan rumus Slovin adalah sebanyak 236 responden. Pengambilan sampel menggunakan teknik Purposive Sampling. Kriteria pemilihan sampel yang telah ditentukan oleh penulis pada penelitian ini adalah:

1. Perusahaan yang dipilih oleh penulis adalah perusahaan manufaktur yang berada di kota Batam.

2. Penulis mengambil kriteria sampel yaitu pada pekerja pendatang perempuan dan laki-laku yang telah bekerja di kota Batam selama 6 bulan. Hal ini karena penulis ingin mengetahui apakah ada reward intrinsik atau reward ekstrinsik yang diterima setelah bekerja beberapa bulan di perusahaan manufaktur dan penulis ingin mengetahui apakah ada tingkat loyalitas kerja bagi tenaga kerja yang telah menerima reward intrinsik atau reward ekstrinsik yang telah diberikan perusahaan.

\section{Teknik Pengumpulan Data}

Penelitian ini menggunakan data primer. Pengumpulan data dalam penelitian ini dilakukan dengan membagikan kuesioner berupa pertanyaan tertulis kepada obyek penelitian dan diisi secara langsung oleh responden.

\section{HASIL DAN PEMBAHASAN \\ Karakateristik Responden}

Berdasarkan kriteria tersebut, sampel yang dapat digunakan dalam penelitian ini berjumlah 239 responden yang ditunjukkan pada gambar 2 dan 3 tentang jenis kelamin dan usia responden.

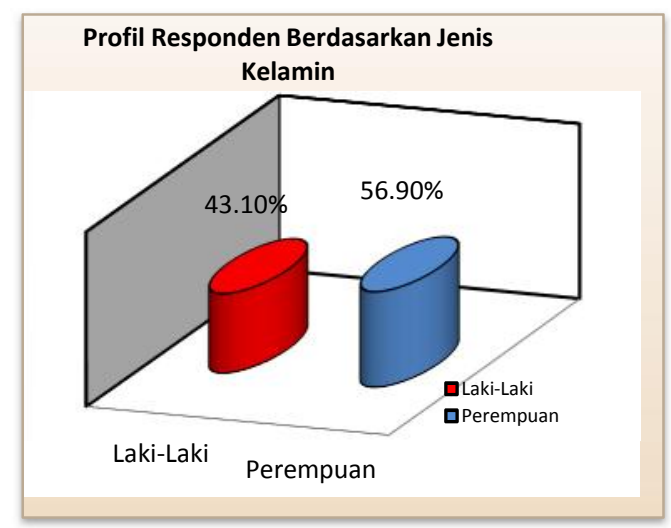

Gambar2: Jenis Kelamin

Sumber: data primer diolah 


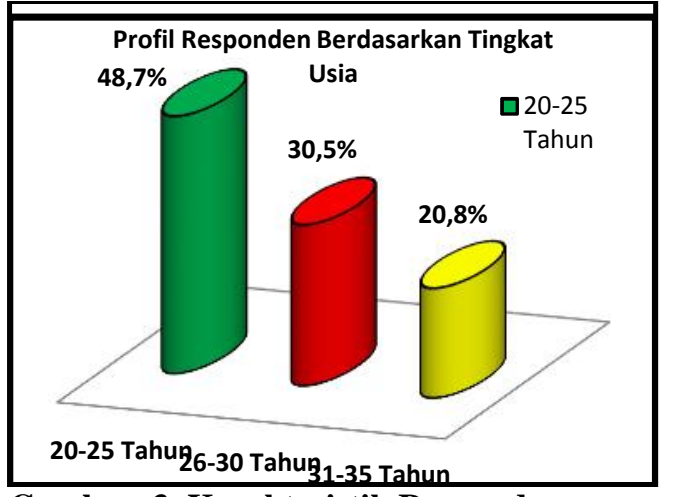

Gambar 3. Karakteristik Responden

Sumber: data primer diolah

Hasil uji validitas untuk masing-masing indikator pertanyaan yang digunakan mempunyai nilai $r$ hitung $>$ r table $(0,316)$, yang berarti indikator pertanyaan dari masingmasing variabel yang digunakan dalam penelitian ini dinyatakan valid untuk digunakan sebagai alat ukur masing-masing variable. Hasil uji reliabilitas semua variabel memiliki nilai alpha-Cronbach lebih besar dari 0.60. Jadi dapat disimpulkan bahwa semua variabel yangdigunakan dalam penelitian ini adalah reliabel.

Hasil uji asumsi klasik yang terdiri dari uji normalitas, uji multikolinearitas, uji heteroskedastitas, dan uji autokorelas sudah memenuhi sesuai dengan syarat yang ditentukan sehingga bisa dilakukan uji hipotesis.

\section{Pengujian Hipotesis}

Analisis Korelasi

Hasil perhitungan uji korelasisebagai berikut:

Tabel 1 Hasil Korelasi

\begin{tabular}{|c|c|c|r|r|r|r|r|}
\hline & & REI & RII & REh & RIH & KK & LK \\
\hline REI & $\begin{array}{c}\text { (One- } \\
\text { tailed) }\end{array}$ & & .000 & .000 & .000 & .000 & .000 \\
\hline RII & $\begin{array}{c}\text { (One- } \\
\text { tailed) }\end{array}$ & .000 & & .000 & .000 & .000 & .000 \\
\hline REH & $\begin{array}{c}\text { (One- } \\
\text { tailed) }\end{array}$ & .000 & .000 & & .000 & .000 & .000 \\
\hline RIH & $\begin{array}{c}\text { (One- } \\
\text { tailed) }\end{array}$ & .000 & .000 & .000 & & .000 & .000 \\
\hline LK & $\begin{array}{c}\text { One- } \\
\text { tailed) }\end{array}$ & .000 & .000 & .000 & .000 & & .000 \\
\hline $\begin{array}{c}\text { (One- } \\
\text { tailed) }\end{array}$ & .000 & .000 & .000 & .000 & .000 & \\
\hline
\end{tabular}

Sumber: data primer diolah

Berdasarkan tabel $1 \mathrm{di}$ atas diketahui nilai signifikansi variabel reward ekstrinsik yang diinginkan (REI), reward intrinsik yang diinginkan (REI), reward ekstrinsik yang diharapkan (REH), reward intrinsik yang diharapkan (RIH), kepuasan kerja dan loyalitas kerja adalah $0.000<0.05$ sehingga dapat disimpulkan bahwa semua variabel mepunyai korelasi atau hubungan yang signifikan.

Hasil perhitungan koefisien korelasi antara Reward Ekstrinsik dan Reward Intrinsik terhadap kepuasan kerja dan loyalitas kerja adalah $\mathbf{0 . 9 3 2 . 3 6}$, berarti kedua variabel tersebut memiliki hubungan yang ERAT dan bentuk hubungannya adalah Linear Positif.

\section{Analisis Independen sampel t-test}

Pengujian hipotesis dengan menggunakan alat uji statistik Independent sampel T-Test dimaksudkan untuk membandingkan rata-rata kepuasan kerja responden laki-laki dan perempuan

1. Uji independen sampel t-test dengan variabel reward ekstrinsik terhadap kepuasan kerja.

Hipotesis yang diajukan adalah:

H1: Terdapat perbedaan persepsi pemberian reward intrinsik terhadap kepuasan kerja berdasarkan gender yaitu laki-laki dan perempuan.

Tabel 2 Uji Independent Sample T-test

Reward Intrinsik terhadap Kepuasan Kerja

\begin{tabular}{cccccc} 
& Gender & N & Mean & $\begin{array}{c}\text { Std. } \\
\text { Deviation }\end{array}$ & $\begin{array}{c}\text { Std.Error } \\
\text { Mean }\end{array}$ \\
\hline $\begin{array}{c}\text { Kepuasan } \\
\text { Kerja }\end{array}$ & Laki-laki & 103 & 3.3262 & .32448 & .03197 \\
& Perempuan & 136 & 3.3529 & .25296 & .02169 \\
\hline
\end{tabular}

Sumber: data primer diolah

Hasil uji independent sample t-test dilihat dari tabel 10 rata-rata sampel bahwa kepuasan kerja berdasarkan laki-laki dan kepuasan kerja berdasarkan perempuan adalah 3.3262 dan 3.3529 dengan perbedaan rata-rata (mean difference) sebesar -0.02 (3.33-3.35) serta standar devisiasi kepuasan kerja berdasarkan laki-laki .32448 dan standar devisiasi kepuasan kerja berdasarkan perempuan adalah .25296 . Hipotesis penelitian rata-rata kepuasan kerja pada laki- laki lebih kecil daripada kepuasan kerja pada perempuan, untuk melihat apakah perbedaan tersebut memang nyata secara statistik maka dapat dilihat dari tabel 3 berikut: 
Ely \& Fatimah, Hubungan Persepsi Pemberian Reward

Reward Intrinsik terhadap Kepuasan Kerja

\begin{tabular}{llrrr}
\hline & & \multicolumn{1}{l}{$\begin{array}{l}\text { Equal } \\
\text { variances } \\
\text { assumed }\end{array}$} & $\begin{array}{l}\text { Equal variances } \\
\text { not assumed }\end{array}$ \\
\hline $\begin{array}{l}\text { Levene's Test for Equality of } \\
\text { Variances }\end{array}$ & $\mathrm{F}$ & 8.012 & \\
\hline $\mathrm{t}$-test for Equality of Means & $\mathrm{t}$ & Sig. & -005 & -692 \\
& & $\mathrm{df}$ & 237 & 187.498 \\
& & Sig. (2-tailed) & .475 & .490 \\
& & Mean Difference & -.02673 & -.02673 \\
& Std. Error & .03735 & .03864 \\
\hline Difference & & -.10031 & -.10294 \\
95\% Confidence Interval of the & Lower & .04685 & .04949 \\
Difference & Upper & & \\
\hline
\end{tabular}

Sumber: data primer diolah

Pengambilan keputusan analisis uji independen sampel t-test dilakukan terlebih dahulu uji kesamaan varian melalui uji $f$ dengan hipotesis:

Dengan kriteria pengujian berdasarkan signifikansi: Ha diterima jika $P$ value $>0.05$ dan Ha ditolak jika $\mathrm{P}$ value $<0.05$. Dengan ini, ditarik kesimpulan bahwa $0.005<0.05$ maka Ha ditolak, kedua varian adalah berbeda dan pengujian t menggunakan Equal Variances Not Assumed.

Analisis uji independen sampel t-tes dilihat dari perbandingan $t$ hitung dan t tabel, apabila $t$ hitung negatif seperti yang terlihat di tabel 3 maka terdapat perbedaan bermakna (H0 ditolak) apabila diterima t hitung $<\mathrm{t}$ tabel. Tabel distribusi t dicari pada $(\alpha) 5 \%: 2=2,5 \%$ (uji 2 sisi) dengan derajat kebebasan (df) n-2 atau 239 - $2=237$. Dengan pengujian dua sisi (signifikansi $=0,025)$ hasil diperoleh untuk $\mathrm{t}$ tabel sebesar 2,2557. Pada tabel 3 terlihat bahwa nilai equal variances not assumed adalah -692.
Ho: kedua varian adalah sama.

Ha: kedua varian adalah berbeda.

Nilai thitung $<\mathrm{t}$ tabel adalah $-692<2,256$ maka dapat disimpulkan bahwa terdapat perbedaan bermakna atau dengan kata lain $\mathrm{H} 1$ diterima. Berdasarkan kesimpulan tersebut maka dapat ditulis persamaan independen sampel t-test sebagai berikut:

$$
\mathbf{t}=\frac{[3.3262-3.3529]-(-12.77455)}{0.03864}
$$

Uji independen sampel t-test dengan variable reward ekstrinsik terhadap kepuasan kerja. Hipotesis yang diajukan adalah:

H2: Terdapat perbedaan persepsi pemberian reward ekstrinsik terhadap kepuasan kerja berdasarkan gender yaitu laki-laki dan perempuan

Tabel 4 Uji Independent Sample T-test

Reward Ekstrinsik terhadap kepuasan kerja

\begin{tabular}{cccccc}
\hline & Gender & $\mathrm{N}$ & Mean & Std.Deviation & $\begin{array}{c}\text { Std.Error } \\
\text { Mean }\end{array}$ \\
\hline $\begin{array}{c}\text { Kepuasan } \\
\text { Kerja }\end{array}$ & $\mathrm{L}$ & 103 & 3.2190 & .31865 & .03140 \\
\hline
\end{tabular}

Sumber: diolah

Hasil uji independent sample t-test dilihat dari tabel 4 rata-rata sampel bahwa kepuasan kerja berdasarkan laki-laki dan kepuasan kerja berdasarkan perempuan adalah 3.2190 dan 3.1863 dengan perbedaan rata-rata (mean difference) sebesar 0.03(3.22-3.19) serta standar devisiasi kepuasan kerja berdasarkan laki-laki .31865 dan standar devisiasi kepuasan kerja berdasarkan perempuan adalah 0.24036 . Hipotesis penelitian rata-rata kepuasan kerja pada laki- laki lebih besar daripada kepuasan kerja pada perempuan, untuk melihat apakah 
perbedaan tersebut memang nyata secara statistic maka dapat dilihat pada tabel 5 berikut ini:

Tabel 5. Uji Independent Sample T-test Reward Ekstrinsik terhadap kepuasan kerja

\begin{tabular}{|c|c|c|c|}
\hline & & $\begin{array}{l}\text { Equal variances } \\
\text { assumed }\end{array}$ & $\begin{array}{l}\text { Equal variances } \\
\text { not assumed }\end{array}$ \\
\hline $\begin{array}{l}\text { Levene's Test for Equality of } \\
\text { Variances }\end{array}$ & Sig. & $\begin{array}{l}10.806 \\
.001\end{array}$ & \\
\hline t-test for Equality of Means $t$ & $\begin{array}{l}\text { df } \\
\text { Sig. (2-tailed) } \\
\text { Mean Difference } \\
\text { Std. Error Difference }\end{array}$ & $\begin{array}{l}.905 \\
237 \\
.366 \\
.03271 \\
.03615\end{array}$ & $\begin{array}{l}.871 \\
183.153 \\
.385 \\
.03271 \\
.03756\end{array}$ \\
\hline $\begin{array}{l}95 \% \text { Confidence Interval of the } \\
\text { Difference }\end{array}$ & $\begin{array}{l}\text { Lower } \\
\quad \text { Upper }\end{array}$ & $\begin{array}{l}-.03851 \\
.10394\end{array}$ & $\begin{array}{l}-.04139 \\
1.0681\end{array}$ \\
\hline
\end{tabular}

Sumber: data primer diolah

Pengambilan keputusan analisis uji independen sampel t-test dilakukan terlebih dahulu uji kesamaan varian melalui uji f dengan hipotesis:

a. Ho: kedua varian adalah sama.

b. Ha: kedua varian adalah berbeda.

Dengan kriteria pengujian berdasarkan signifikansi: Ha diterima jika $P$ value $>0.05$ dan Ha ditolak jika $\mathrm{P}$ value $<0.05$. Dengan ini, ditarik kesimpulan bahwa $0.001<0.05$ maka Ha ditolak, kedua varian adalah berbeda dan pengujian t menggunakan Equal Variances Not Assumed.

Analisis uji independen sampel t-tes dilihat dari perbandingan $\mathrm{t}$ hitung dan $\mathrm{t}$ tabel, apabila $t$ hitung positif berarti rata-rata grup 1 (Laki-laki) lebih tinggi daripada grup 2 (Perempuan) seperti yang terlihat di tabel 5 dengan $\mathrm{H} 1$ diterima apabila $\mathrm{t}$ hitung $>\mathrm{t}$ tabel. Tabel distribusi t dicari pada $(\alpha) 5 \%: 2=2,5 \%$ (uji 2 sisi) dengan derajat kebebasan (df) $n-2$ atau $239-2=237$. Dengan pengujian dua sisi (signifikansi $=0,025)$ hasil diperoleh untuk $\mathrm{t}$ tabel sebesar 2,2557. Pada tabel 4.13 terlihat bahwa nilai pada equal variance not assumed adalah 871 . Nilai t hitung < t tabel yaitu $871<$ 2,2556 maka disimpulkan bahwa tidak terdapat perbedaan bermakna atau dengan kata lain $\mathrm{H} 0$ diterima. Berdasarkan kesimpulan tersebut maka dapat ditulis persamaan independen sampel t-test sebagai berikut:

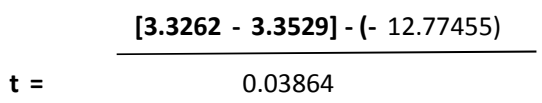

\section{Analisis Data}

Tabel 6 Ringkasan Hasil Analisis Korelasi

\begin{tabular}{|l|c|c|}
\hline \multicolumn{1}{|c|}{ Hipotesis } & Sig. & Hasil \\
\hline $\begin{array}{l}\text { H1a: Terdapat } \\
\text { hubungan pemberian } \\
\text { reward intrinsik yang } \\
\text { diinginkan secara }\end{array}$ & 0.000 & Terdukung \\
$\begin{array}{l}\text { positif terhadap } \\
\text { kepuasan kerja } \\
\text { karyawan. }\end{array}$ & & \\
\hline $\begin{array}{l}\text { H1b: Terdapat } \\
\text { hubungan pemberian } \\
\text { reward } \text { ekstrinsik } \\
\text { yang diinginkan } \\
\text { secara positif } \\
\text { terhadap kepuasan } \\
\text { kerja karyawan }\end{array}$ & 0.000 & Terdukung \\
\hline $\begin{array}{l}\text { H2a: Terdapat } \\
\text { hubungan pemberian } \\
\text { reward intrinsik yang } \\
\text { diharapkan secara }\end{array}$ & 0.000 & Terdukung \\
$\begin{array}{l}\text { positif terhadap } \\
\text { kepuasan kerja } \\
\text { karyawan }\end{array}$ & & \\
\hline $\begin{array}{l}\text { H2b: Terdapat } \\
\text { hubungan pemberian } \\
\text { reward ekstrinsik } \\
\text { yang diharapkan } \\
\text { secara positif } \\
\text { terhadap kepuasan } \\
\text { kerja karyawan. }\end{array}$ & 0.000 & Terdukung \\
\hline $\begin{array}{l}\text { H3a: Terdapat } \\
\text { hubungan } \text { reward } \\
\text { intrinsik yang } \\
\text { diinginkan terhadap } \\
\text { loyalitas kerja } \\
\text { karyawan. }\end{array}$ & 0.000 & Terdukung \\
\hline $\begin{array}{l}\text { H3b: Terdapat } \\
\text { hubungan reward } \\
\text { ekstrinsik yang }\end{array}$ & & \\
\hline
\end{tabular}


Ely \& Fatimah, Hubungan Persepsi Pemberian Reward

\begin{tabular}{|l|c|c|}
\hline \multicolumn{1}{|c|}{ Hipotesis } & Sig. & Hasil \\
\hline $\begin{array}{l}\text { diinginkan terhadap } \\
\text { loyalitas kerja } \\
\text { karyawan. }\end{array}$ & & \\
\hline $\begin{array}{l}\text { H4a: Terdapat } \\
\text { hubungan reward } \\
\text { intrinsik yang } \\
\text { diharapkan terhadap } \\
\text { loyalitas kerja } \\
\text { karyawan. }\end{array}$ & 0.000 & Terdukung \\
\hline $\begin{array}{l}\text { H4b: Terdapat } \\
\text { hubungan reward } \\
\text { ekstrinsik yang } \\
\text { diharapkan terhadap } \\
\text { loyalitas kerja } \\
\text { karyawan }\end{array}$ & 0.000 & Terdukung \\
\hline
\end{tabular}

Sig. pada $\alpha=5 \%$

Hubungan pemberian reward ekstrinsik dan reward intrinsik yang diinginkan terhadap kepuasan kerja karyawan

Berdasarkan hasil uji statistik, menunjukkan bahwa H1a dan H1b terdukung, yang berarti terdapat hubungan positif antara reward ekstrinsik dan reward intrinsik yang diinginkan terhadap kepuasan kerja karyawan. Hasil ini menjukkan bahwa reward ekstrinsik dan reward intrinsic yang diinginkan dapat berhubungan terhadap kepuasan kerja karyawan dalam menyelesaikan pekerjaannya. Nilai sig. dari reward ekstrinsik dan reward intrinsik diinginkan sebesar 0.000 berarti $<0.05$ yang berarti bahwa reward ektrinsik dan reward intrinsik yang diinginkan memiliki hubungan positif terhadap kepuasan kerja karyawan.

Hasil penelitian ini sejalan dengan penelitian lain yang dilakukan oleh Zaini et al (2009) dan Chew (2005) menemukan bahwa kepuasan kerja berhubungan dengan reward intrinsik seperti membayar, promosi, dan bonus dan reward ekstrinsik adalah salah satu variabel penjelas yang paling penting dalam kedua sektor ekonomi dan sosialis.

Hubungan pemberian reward ekstrinsik dan reward intrinsik yang diharapkan terhadap kepuasan kerja karyawan

Berdasarkan hasil uji statistik yang telah dijelaskan di atas, menunjukkan bahwa $\mathrm{H} 2 \mathrm{a}$ dan $\mathrm{H} 2 \mathrm{~b}$ terdukung, yang berarti terdapat hubungan positif antara reward ekstrinsik dan reward intrinsik yang diharapkan terhadap kepuasan kerja karyawan. Hasil ini menjukkan bahwa reward ekstrinsik dan reward intrinsik yang diharapkan dapat berhubungan terhadap kepuasan kerja karyawan dalam menyelesaikan pekerjaannya. Nilai sig. dari reward ekstrinsik dan reward intrinsik diinginkan sebesar 0.000 berarti < 0.05 yang berarti bahwa reward ektrinsik dan reward intrinsik yang diharapkan memiliki hubungan positif terhadap kepuasan kerja karyawan.

Penelitian ini mendukung penelitian yang dilakukan oleh Linz dan Semykina (2011) bahwa kedua imbalan ekstrinsik dan intrinsik yang diharapkan akan positif terkait dengan kepuasan kerja, reward yang diharapkan akan lebih peduli untuk imbalan moneter daripada imbalan non-moneter. Imbalan moneter memiliki pengaruh yang besar terhadap kepuasan kerja. Selain itu, Locke (1976) juga menghubungkan kepuasan kerja dan reward yang diharapkan atau berdasarkan aspek pekerjaan.

\section{Hubungan pemberian reward ekstrinsik dan reward intrinsik yang diinginkan terhadap loyalitas kerja karyawan.}

Berdasarkan hasil uji statistik menunjukkan bahwa H3a dan H3b terdukung, yang berarti terdapat hubungan positif antara reward ekstrinsik dan reward intrinsik yang diinginkan terhadap loyalitas kerja karyawan. Hasil ini menjukkan bahwa reward ekstrinsik dan reward intrinsik yang diinginkan dapat berhubungan terhadap loyalitas kerja karyawan dalam menyelesaikan pekerjaannya. Nilai sig. dari reward ekstrinsik dan reward intrinsik diinginkan sebesar 0.000 berarti $<0.05$ yang berarti bahwa reward ektrinsik dan reward intrinsik yang diinginkan memiliki hubungan positif terhadap loyalitas kerja karyawan.

Hasil penelitian ini sejalan dengan penelitian sebelumnya yang dilakukan oleh Linz et al (2013) mengemukakan dalam penelitiannya, hubungan positif yang kuat terhadap loyalitas jelas diantara tenaga kerja yang menginginkan keamanan kerja, pujian dari atasan, dan kesempatan untuk mengembangkan keterampilan baru atau mencapai sesuatu yang berharga. Dalam penelitiannya juga mengemukakan terdapat hubungan positif antara loyalitas dan pendapatan. Kontribusi loyalitas terhadap pendapatan untuk beberapa kelompok pekerja ditemukan menjadi lebih besar dari satu tahun tambahan pelatihan atau pengalaman kerja. Penelitian lain yang 
dilakukan oleh Tolbize (2008) juga menyatakan bahwa loyalitas akan lebih kuat di antara pekerja yang menunjukkan keinginan mereka untuk meningkatkan proses kerja.

\section{Hubungan pemberian reward ekstrinsik dan reward intrinsik yang diharapkan terhadap loyalitas kerja karyawan.}

Berdasarkan hasil uji statistik menunjukkan bahwa $\mathrm{H} 4 \mathrm{a}$ dan $\mathrm{H} 4 \mathrm{~b}$ terdukung, yang berarti terdapat hubungan positif antara reward ekstrinsik dan reward intrinsik yang diharapkan terhadap loyalitas kerja karyawan. Hasil ini menunjukkan bahwa reward ekstrinsik dan reward intrinsik yang diharapkan dapat berhubungan terhadap loyalitas kerja karyawan dalam menyelesaikan pekerjaannya. Nilai sig. dari reward ekstrinsik dan reward intrinsik diinginkan sebesar 0.000 berarti $<0.05$ yang berarti bahwa reward ektrinsik dan reward intrinsik yang diharapkan memiliki hubungan positif terhadap loyalitas kerja karyawan.

Hasil penelitian ini sejalan dengan penelitian yang dilakukan Linz et al (2013) mengemukakan bahwa loyalitas pekerja secara positif terkait dengan sejumlah reward yang diharapkan. Meningkatkan frekuensi atau jumlah bonus yang diberikan kepada tenaga kerja, memberikan kesempatan tambahan untuk mengembangkan keterampilan, dan mengidentifikasi dan mempromosikan kegiatan yang berkontribusi terhadap keamanan kerja juga muncul untuk meningkatkan loyalitas antara tenaga kerja. Reward yang diharapkan bertemu menyebabkan kepuasan kerja serta komitmen berorganisasi yang akan menimbulkan tindakan loyalitas.

\section{Perbedaan pemberian reward ekstrinsik dan reward intrinsik terhadap Kepuasan kerja kerja karyawan berdasarkan gender}

Terdapat 2 hasil pengujian dari analisis independen sampel t- test:

1. Hasil pengujian secara statistik dan pengelolahan data menunjukkan terdapat perbedaan persepsi pemberian reward intrinsik terhadap kepuasan kerja berdasarkan gender yaitu laki-laki dan perempuan. Skor reward intrinsik terhadap kepuasan kerja antara laki-laki dan perempuan yaitu kepuasan kerja laki-laki lebih rendah dibandingkan perempuan. Hal tersebut bisa dilihat dari skor mean kepuasan kerja laki-laki lebih rendah dari skor mean kepuasan kerja pada perempuan. Penelitian ini menunjukkan bahwa pemberian reward intrinsik berpengaruh terhadap kepuasan kerja pada perempuan. Tenaga kerja perempuan tersebut merasa puas oleh pemberian reward intrinsik yang diberikan oleh perusahaan karena telah sesuai dengan kontribusi dan tanggung jawab mereka kepada perusahaan. Perusahaan memberikan kesempatan tenaga kerja untuk mencapai kinerja yang lebih, memberikan lingkungan kerja yang mendukung, kebebasan dalam bekerja. Hal ini sesuai dengan pernyataan Robbins (2001) bahwa kepuasan kerja akan terdorong oleh pemberian reward yang pantas, kondisi kerja yang mendukung, dan adanya keramahan dari sesama rekan kerja. Pemberian reward tersebut membuat tenaga kerja perempuan tersebut merasa enggan untuk pindah ke perusahaan lain dan dapat meminimalkan jumlah karyawan yang keluar dari perusahaan untuk bergabung ke perusahaan lain.

Hasil penelitian ini sama hasilnya dengan penelitian Bartol (1976) dan Mottaz (1985) bahwa tenaga kerja perempuan lebih cenderung puas dengan pemberian berupa reward intrinsik (reward yang terkait dengan pekerjaan itu sendiri) seperti kesempatan untuk mempelajari hal-hal baru, kebebasan pada pekerjaan. Hasil penelitian ini di dukung juga oleh penelitian yang dilakukan oleh Saner dan Eyupoglu (2011) bahwa dosen perempuan di Universitas mempunyai tingkat kepuasan lebih tinggi daripada dosen laki-laki.

2. Hasil pengujian secara statistik dan pengelolahan data menunjukkan tidak terdapat perbedaan persepsi pemberian reward ekstrinsik terhadap kepuasan kerja berdasarkan gender yaitu laki-laki dan perempuan. Skor reward ekstrinsik terhadap kepuasan kerja antara laki-laki dan perempuan yaitu kepuasan kerja laki-laki lebih sedikit tinggi dibandingkan perempuan. Hal tersebut bisa dilihat dari skor mean kepuasan kerja laki-lakilebih tinggi dibandingkan dengan skor mean kepuasan kerja pada perempuan. Hasil penelitian ini sama hasilnya dengan penelitian yang dilakukan oleh Penelitian yang dilakukan oleh Ringkas dan Aldag (1975), Ringkas dan Oliver (1976) 
Ely \& Fatimah, Hubungan Persepsi Pemberian Reward

menemukan tidak ada perbedaan yang signifikan antara persepsi pemberian reward ekstrinsik terhadap kepuasan kerja pada lakilaki dan perempuan. Hal ini berarti kepuasan kerja yang dirasakan oleh laki-laki dan perempuan belum terpenuhi oleh perusahaan. Sistem pemberian reward yang dimiliki perusahaan belum bekerja secara memadai untuk memenuhi keinginan dan harapan dari tenaga kerja.

\section{KESIMPULAN}

Berdasarkan hasil penelitian mengenai reward ekstrinsik yang diinginkan, reward intrinsik yang diinginkan, reward ekstrinsik yang diharapkan, reward intrinsik yang diharapkan, kepuasan kerja dan loyalitas kerja pada perusahaan manufaktur yang ada di kota Batam, penulis dapat mengambil kesimpulan dari perumusan masalah sebagai berikut:

1. Reward ekstrinsik dan reward intrinsik yang diinginkan berhubungan positif dan signifikan terhadap kepuasan kerja dan loyalitas kerja. Hal ini disebabkan karena perusahaan menghargai kontribusi yang diberikan oleh tenaga kerja tersebut sehingga tenaga kerja tersebut merasa puas dan tetap meningkatkan produktivitas dan berkompetisi secara sehat. Pemberian reward yang sesuai dapat membuat tenaga kerja tidak berpindah ke perusahaan lain dan tetap bersikap loyal kepada perusahaan.

2. Reward ekstrinsik dan reward intrinsik yang diharapkan berhubungan positif dan signifikan terhadap kepuasan kerja dan loyalitas kerja. Hal ini berarti apa yang diharapkan oleh tenaga kerja terpenuhi oleh pemberian reward yang sesuai yang diberikan perusahaan sehingga mempengaruhi perilaku tenaga kerja terkait dengan pekerjaan dan perusahaan yaitu meningkatnya tingkat loyalitas tenaga kerja kepada perusahaan.

3. Terdapat perbedaan reward intrinsik terhadap kepuasan kerja berdasarkan gender yaitu perempuan lebih cenderung puas dengan pemberian reward intrinsik dibandingkan laki-laki. Perusahaan hanya berfokus pada pemberian reward intrinsik karena reward tersebut sangat terkait dengan pekerjaan dan dapat meningkatkan produktivitas perusahaan. Hal ini juga dapat meminimalkan biaya yang dikeluarkan perusahaan seperti bonus dan jaminan yang dibutuhkan oleh setiap tenaga kerja.

4. Tidak terdapatnya perbedaan pemberian reward ekstrinsik terhadap kepuasan kerja berdasarkan gender yaitu laki-laki dan perempuan. Hal ini dikarenakan rendahnya apresiasi dari perusahaan atas kontribusi yang dihasilkan tenaga kerja. Perusahaan seharusnya mempunyai system pemberian reward yang sesuai agar kepuasan kerja antar tenaga kerja. Pentingnya tingkat kepuasan kerja antar tenaga kerja dapat meningkatkan produktivitas dan efisiensi waktu dalam bekerja karena tenaga kerja telah merasa puas dalam menerima reward yang sesuai dengan kontribusi yang dilakukan.

\section{DAFTAR PUSTAKA}

Abdullah, R. B., MUSA, M. Z., R, R. H., \& K. K. (2011). The study of employee satisfaction and its effect on loyalty in hotel industry in Klang Valley, Malaysia. International Journal of Business and Social Science, Vol 2 No.3,pp. 147-155.

Alex S. Nitisemito, 2014, Manajemen Personalia, Ghalia Indonesia, Jakarta

Arnold, H., \& Feldman, D. (1982). A multivariate Analysis of the Determinants of Job Turnover. Journal of Applied Psychology, 67 (3) 350-360.

Artz, B. (2010). A multivariate analysis of the determinants of job turnover. International Journal of Manpower, Vol.31 No.6 pp 6256644.

Bartol, K. (1976). Relationship of sex and professional training area to job orientation . Journal of Applied psychology, Vol.61 No.3 pp.368-370.

Bratton, J., \& Gold, J. (1994). Human Resource Management Theory and Practice Basingtoke. Macmillan.

Brief, A., \& Aldag, R. (1975). Male-Female Differences in Work Attitudes Amon Retail Sales Manager. Journal of Applied Psychology, 305-414.

Brief, A., \& Oliver, R. (1976). Male-female differences in work attitudes among retail sales Manager. Journal of Applied Psychology, 526-528.

Carroll, B. (1969). Job satisfaction: A review of Slitearture . New York: New York State School of Industrial and Labor Relations. 
Clifford, J. (1985). The Relative Importance of Intrinsic and Extrinsic Rewards as Determinants of Work Satisfaction. Soc.Quart, 365-385.

Flippo, E. (1996). Manajemen Personalia Edisi 2. Jakarta: Erlangga.

Hasibuan, M. (2001). Manajemen Sumber Daya Manusia(Edisi Revisi). Jakarta: Bumi Aksara.

Jogyanto. (2004). Metodologi Penelitian Bisnis. Jogyakarta: BPFE-Yogyakarta.

Kaiser, Lutz. (2005). Gender-Job Satisfaction Differences across Europe: An Indicator for Labor Market Modernization. IZA Bonn, DIW Berlin and EPAG.

Kerlinger. (2006). Asas-asas Penelitian Behavioral. Yogyakarta: Gadjah Mada University Press.

Linz, S., \& Semykina, A. (2011). What makes workers happy? Anticipated rewards and job satisfaction. Industrial Relations.

Linz, S., Linda, K. G., \& Busch, M. (2013). Promoting Workers Loyalty: an Empirical Analysis. International Journal of Manpower.

Locke, E. (1976). The nature and causes of job satisfaction. Handbook of Industrial and Organizational Psychology, 1297-1349.

Luthans, F. (2006). Perilaku Organisasi, Edisi sepuluh. Yogyakarta: Andi.

Ma'arif, M. S., Sukmawati, A., \& Damayanti, D. (2013). Faktor-faktor yang Mempengaruhi Kinerja Pegawai: Studi di Perusahaan Daerah Pasar Tohaga Kabupaten Bogor. Jurnal Aplikasi Manajemen.Vol 11 no 2, 241-249

Milne. (2007). Motivation, incentives and organizational culture. Journal of Knowledge Management. Vol. 11 Issue: 6, pp.28-38

Mottaz, C. (1985). The Relative Importance of Intrinsic and Extrinsic Rewards as Determinants of Work Satisfaction. Sociological Quaterly.

Newman, A., \& Sheikh, A. (2012). Organizational commitment in Chinese small- and medium-sized enterprises: The role of extrinsic, intrinsic, and social rewards. The Internatioanl Journal of Human Resource Management. Vol 23 No 2
Priya, T.U., \& Eshwar. (2014). Rewards, Motivation and Job Satisfaction of Employees in Commercial Banks - An Investigative Analysis. International Journal of Academic Research in Bussiness and Social Sciences. Vol 4 No 4

Rehman, M. Z.U., Khan,M.R.,Ziauddin \& Lashari, J. A. (2010). Effect of job reward on job satisfaction,moderating role of age differences: An empirical evidence from Pakistan. Africal Journal Business Management. Vol 4 No 6

Robbins, S. (2001). Perilaku Organisasi,Konsep, Kontroversi, Aplikasi. Jakarta: PT.Prenhallindo.

Rohmini, S. (2011). Hubungan Pemberian Kesejahterahan dan Suasana Kerja dengan Loyalitas Kerja Perawat di Rumah Sakit Islam Muhammadiyah Kendal. Skripsi Universitas Muhammadiyah Semarang.

Ruvendi, R.(2005). Pengaruh Imbalan dan Gaya Kepemimpinan terhadap Kepuasan Kerja karyawan di Balai Besar Industri hasil Pertanian Bogor. Jurnal Ilmiah Binaniaga Vol 1 No 1.

Saner.T. \& Eyupoglu.Z.(2011). Have a Gender Differences in Job Satisfaction Dissapeared? A study of Turkish universities in North Cyprus. African Journal Bussiness Management.

Sudimin, T. (2003). Whistleblowing: Dilema Loyalitas dan Tanggung Jawab Publik. Jurnal Manajemen dan Usahawan.Vol 12 No 11.

Tolbize, A. Generational Differences in the workplace. Research and Training Cente on Community Living. University of Minnesota, Minneapolis.

Trianasari, Y. (2005). Hubungan Antara Persepsi Terhadap Insentif dan Lingkungan Kerja dan Loyalitas Kerja. Skripsi, Fakultas Psikologi Universitas Muhammadiyah Yogyakarta

Vroom, V. (1964). Work and Motivation. New York: NY.

Wanous, J., Poland, T., Premack, S., \& Shannon Davis, K. (1992). The effects of met expectations on newcomer attitudes and behaviors: a review and meta-analysis. Journal of Applied Psychology. 77(3):28897 
Ely \& Fatimah, Hubungan Persepsi Pemberian Reward

Wibowo. (2012). Manajemen Kinerja. Jakarta: Rajawali Pers.

Wong, M., Gardiner, E., Lange, W., \& Coulon, L. (2008). Generational differences in personality and motivation. Journal of Managerial Psychology, 878-890.
Zaini, A., \& Nilufar, S. S. (2009). The effect of human resource management practices on business performance among private companies in Malaysia. International Journal of Business and Management, 23 (8). pp. 878-890. 